Original Research Article

\title{
Dental students' perceptions and feedback on teaching and learning pharmacology
}

\author{
Amit P. Patel, Savitri Katlam*
}

Department of Pharmacology, MGM Medical College and Hospital, Kamothe, NaviMumbai, Maharashtra, India

Received: 06 July 2017 Accepted: 29 July 2017

\section{*Correspondence to:}

Savitri Katlam,

Email: savitrikatlam@ gmail.com

Copyright: (C) the author(s), publisher and licensee Medip Academy. This is an openaccess article distributed under the terms of the Creative Commons Attribution NonCommercial License, which permits unrestricted noncommercial use, distribution, and reproduction in any medium, provided the original work is properly cited.

\begin{abstract}
Background: There is a shift in the teaching learning process with the advent of newer methodologies. The present study was conducted to obtain feedback from 2 year dental students regarding teaching and learning methodology and their perception about pharmacology.

Methods: This was an observational, cross-sectional questionnaire based survey. A self-designed questionnaire containing 10 questions with 4-6 options regarding the teaching and learning methodology was given to 2nd year dental students. Responses was collected and data was compiled in Microsoft excel and statistically analyzed.

Results: A total of 97 students participated in this survey. Students opinion revealed that, Gastrointestinal followed by general pharmacology and cardiovascular system were the most favorite topics. Majority preferred studying from "standard text books" and method of learning was "understanding" of the subject rather mugging. Majority of the students said that preferred lectures taken via LCD projectors and rated viva and MCQ as preferred method of evaluation university exams. Interactive classes and tutorials were the most preferred techniques.

Conclusions: The study concluded that interactive classes and overhead /LCD based lectures should be inculcated in routine learning and teaching program of pharmacology. There is a need to qualitatively assess the various teaching and learning methods, so as to understand students views and their perception for improving teaching and learning pharmacology. The outcome will help us to modify and improve quality of under graduate dental pharmacology teaching and learning.
\end{abstract}

Keywords: Dental, Learning, Perception, Pharmacology, Teaching

\section{INTRODUCTION}

Medical education is challenged to adopt and develop modern pedagogic methodologies that can enhance and supplement the conventional lecture teaching in order to promote active learning, problem solving and critical thinking among students. ${ }^{1-3}$

Pharmacology as a subject is introduced in $2^{\text {nd }}$ year of various health sciences courses like MBBS, dentistry, physiotherapy, nursing etc. Good learning and understanding of this subject helps newly graduated health professionals to acquire efficient prescribing skills and aims towards proper rationale treatment and cure of various ailments. ${ }^{4,5}$ The aim of teaching pharmacology is to impart knowledge, attitude and skills. Hence choice of teaching and learning strategies plays an important role. ${ }^{3}$

It is accepted that the feedback from students serves as an effective tool in developing teaching methodology and evaluation methods in undergraduate teaching. ${ }^{6,7}$

Several studies in medical field have addressed and evaluated the teaching and learning methodology so as to understand the difficulties students face and to bring in changes and modification in methodologies for imparting sound knowledge of pharmacology. ${ }^{6-9}$ However there 
exists paucity in literature with regard to dental students and hence the present study was conducted to assess the dental student's attitude, perception and feedback on teaching-learning methodology and evaluation methods in pharmacology.

It is very important for reviewing the teaching and learning program at regular interval which will eventually help us. The perception of students and their attitude towards teaching, learning and evaluation methods can help us throw more light on difficulties students have regarding pharmacology and also on how teaching and learning of this subject can be made more fun filled and interesting. It will explore which methods can be incorporated to make teaching and learning of pharmacology effective.

\section{METHODS}

Study was carried out in Department of pharmacology and Population of the study was Undergraduate Dental students studying in $2^{\text {nd }}$ year. It was cross-sectional, observational, questionnaire based survey. Which was done from January - February 2016 (2 months).

\section{Inclusion criteria}

- All the undergraduate $2^{\text {nd }}$ year dental students studying pharmacology

- Participants willing for Informed consent

\section{Study tool}

Self designed questionnaire (10 item teaching and learning questionnaire).

\section{Procedure}

Undergraduate students studying in the $2^{\text {nd }}$ year of dental were approached to participate in this study. The study purpose and details were briefed to the students. We included students fulfilling the inclusion criteria. We excluded the $1^{\text {st }}, 3^{\text {rd }}$ and $4^{\text {th }}$ year undergraduate students, students unwilling to participate and not willing for informed consent. Participants were explained the purpose of the study and were requested to complete the selfdesigned 10 item teaching and learning questionnaire. After 20mins the complete questionnaire survey form were collected and analysed.

\section{Statistical analysis}

Data was entered in Microsoft Excel 2007 and statistically analyzed. Data was expressed in descriptive statistics i.e. actual number and percentage.

\section{RESULTS}

A total of 97 dental students participated in this study. Topics found interesting by students were gastro-intestinal system $(58.75 \%)$, followed by general pharmacology
(46.39\%) and cardiovascular system (41.24\%) The least liked topics were autonomic nervous system (10.31\%), autocoids $(7.22 \%)$ and chemotherapy $(5.15 \%)$. (Figure 1 ).

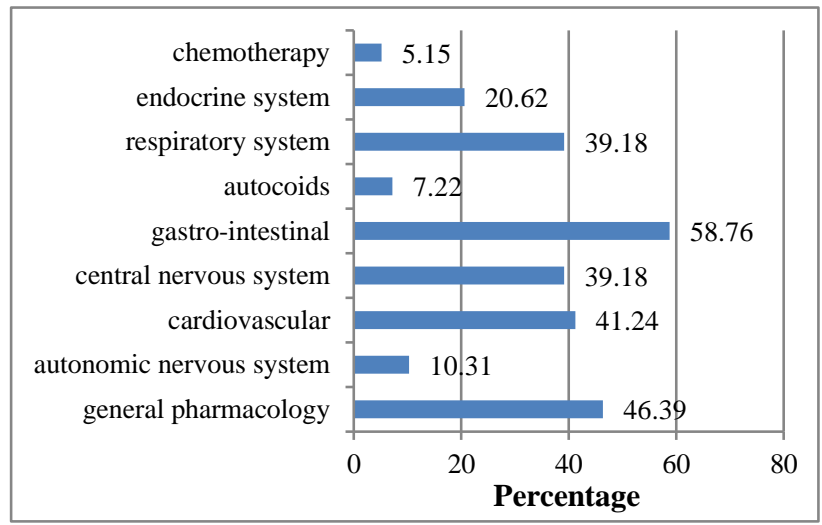

Figure 1: Topic found interesting in pharmacology by dental students.

Majority of the students $(56.7 \%)$ preferred standard textbook as studying material (Figure 2) and the method of learning was "understanding" $(61.86 \%)$ of the subject (Figure 3). Interactive classes (46.39\%) and tutorials were the most interesting teaching learning method.

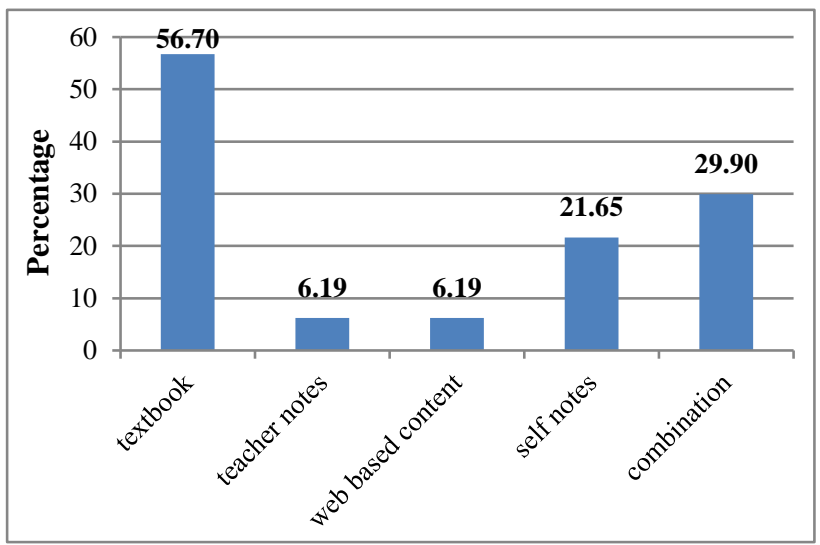

Figure 2: Preferred study materials to learn pharmacology by dental students.

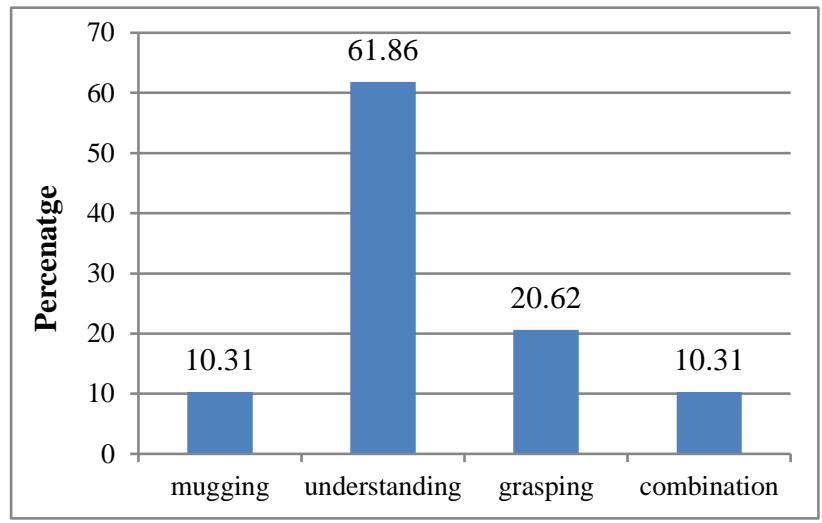

Figure 3: Preferred method of learning pharmacology by dental students. 
Majority (43.30\%) of the students preferred lecture conducted using overhead / LCD projected as a teaching over conventional chalk and board lectures. (Figure 4).

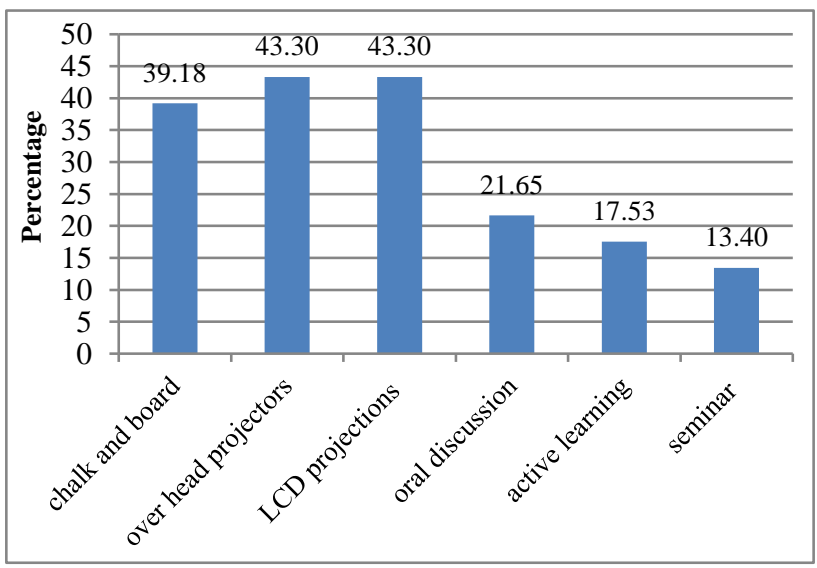

Figure 4: Preferred mode of teaching pharmacology by dental students.

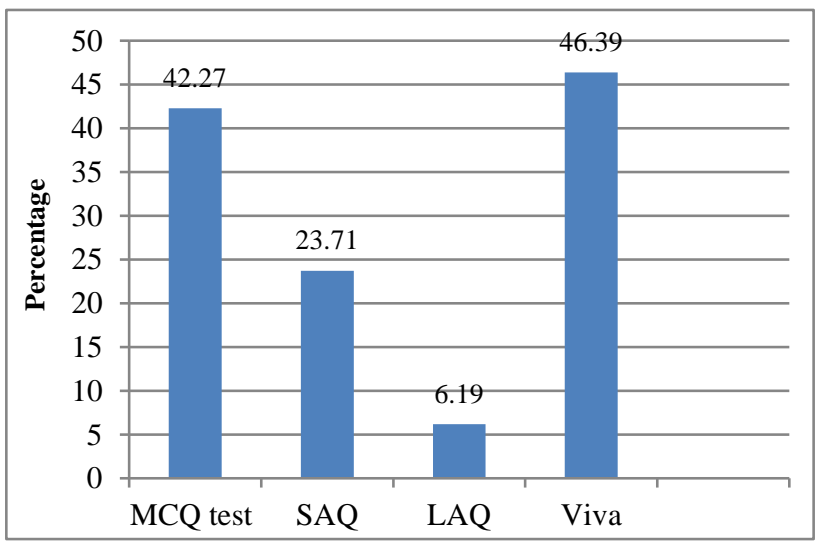

Figure 5: Preferred evaluating method for examination in pharmacology by dental students.

Seventy percent students said that a time period of 1 year is adequate for teaching pharmacology and rated viva (46.39\%) and MCQ (42.27\%) as good evaluation methods for preparation of annual university exam. (Figure 5).

\section{DISCUSSION}

Pharmacology forms the backbone of rational therapeutics, being both a basic and applied science. Student's perception and attitude towards teaching, learning and evaluation methods are important in bringing in changes and modifications in the course for betterment of students and teachers as well.

In the present study, many important things were understood. Based on the student's responses to questionnaire, their favourite topics documented in our study was gastro-intestinal system followed by general pharmacology and cardiovascular system. The least liked topics were autonomic nervous system, autocoids and chemotherapy.
In a similar study conducted by Tabish et al, they documented that majority of the students found general pharmacology, cardiovascular system and central nervous system as the most important topics and Autonomic nervous system, autocoids and respiratory system as the least interesting topics. ${ }^{8}$ In a study conducted by Bhosale et al, they documented that majority of the students found CVS, CNS, general pharmacology as most interesting while Autonomic nervous system, respiratory system and autocoids were least liked topics in pharmacology. ${ }^{7}$ Thus, our documented findings are similar to preferred topic/ system in pharmacology as documented by Bhosal et al and Tabish et al. ${ }^{7,8}$ This could be due to the ease of understanding and maybe appealing topic in pharmacology.

It seems that there is a need to improve the method of delivering these least liked topics in a manner which can raise interest and understanding of such topic. These topics needs to be emphasized more to draw attention of students. This can be done by utilizing their suggestions like use of micro teaching sessions, problem based learning, patient related teaching and interactive teaching with strict bilateral communications in conventional teaching. Involvement of students improves learning and their performance in exams.

In our study, majority of the students preferred standard textbook as studying material. Studies conducted by Bhosal et al and Tabish et al, have also documented the standard textbook as most preferred method for learning. ${ }^{7,8}$ Study conducted by Rani et al, has documented that standard textbook and teacher's notes being preferred the most. ${ }^{4}$ It is important to emphasis to refer standard textbooks as they are usually recommended by the course stakeholders and the information printed provides authentic and trustworthy source of information. The concepts are explained in details with diagram. The flow of the language is simple and good and helps in understanding and retention of the subject which is otherwise not possible through cramped up notes.

In this study, majority students felt that interactive classes and tutorials was the most interesting method of teaching and learning. Conventional lectures are one sided and teacher oriented teaching tool. It doesn't allow the teacher to know whether the students are understanding and does not involve the student participation for active learning. In interactive classes, the participation is both sided (teacher and student). The students are free to express their difficulties and doubts and promote active learning.

The present study documented that, majority of the students preferred lecture conducted using overhead / LCD (powerpoint) projected as a teaching over conventional chalk and board lectures. Conventional chalk and board lectures are slow and time consuming and it is often difficult to explain the core concepts of pharmacology in the given span of time. Also, the teacher's attention is divided between writing on board and delivery of lecture. 
Thus, LCD and overhead projectors offer the benefit of better time management, feasibility of explaining core concepts in depth with better audio-visual presentation thereby enhancing quality of the lecture. However, one needs to anticipate the time and efforts for making such presentations.

In this study, majority student's rated voice-viva and MCQ as good evaluation method for preparation of exam. This finding is similar to Prasad et al, in which voice viva and written exams helped them to prepare for final examination. $^{9}$

The study has few limitations. The study was conducted in a single setup and sample size was moderate. Qualitative assessment was not done. The survey questionnaire used was a self-designed based on earlier studies. Further multiple and institutional level studies are warranted to explore and implement the best method for teaching and learning in pharmacology.

\section{CONCLUSION}

The study concluded that interactive classes and overhead/ LCD based lectures should be inculcated in routine learning and teaching program of pharmacology. There is a need to qualitatively assess the various teaching and learning methods, so as to understand students views and their perception for improving teaching and learning pharmacology. The outcome will help us to modify and improve quality of under graduate dental pharmacology teaching and learning.

\section{ACKNOWLEDGEMENTS}

Authors would like to thank the study participants for their support and co-operation.

Funding: No funding sources Conflict of interest: None declared

Ethical approval: The study was approved by the Institutional Ethics Committee

\section{REFERENCES}

1. Ananthakrishnan N, Sethuraman KR, Kumar S. Principles and practice. 2nd ed. Pondicherry: Alumni Association of National Teacher Training Centre, JIPMER; Medical education: 2000.
2. Srikanth S, Thirunaaukarasu, Behera B, Mahajan P. Modular Teaching: An Alternative to Routine Teaching Method for Undergraduate Medical Students. Indian J Community Med. 2011;36(3):2378.

3. Council of India. Medical Council of India Regulations on Graduate Medical Education 1997 (Amended up to $8^{\text {th }}$ October 2016). Available at: http://www.mciindia.org/Rules-and-

Regulation/GME_REGULATIONS.pdf .

4. Rani V, Tekulapally K, Shyamala R, Simpson GB. Assessment of effectiveness of different teaching methodologies and perception about pharmacology among 2nd year dental students: A cross-sectional study. International Journal of Health and Allied Sciences. 2017;6(2):64.

5. Thirunavukkarasu J, Latha K, Sathish BC, Tharani CB. A Study of effectiveness of different teaching methodology in pharmacology for undergraduate students. Asian J Exp Biol Sci. 2011;2(3):487-92.

6. Chavda N, Yadav P, Chaudhari M, Kantharia ND. Second year student feedback on teaching methodology and evaluation methods in pharmacology. Natl J Physio Pharma Pharmacol. 2011;1:23-31.

7. Bhosale UA, Yegnanarayan R, Yadav GE. Attitude, perception and feedback of second year medical students on teaching-learning methodology and evaluation methods in pharmacology: A questionnaire-based study. Nigerian medical journal: journal of the Nigeria Medical Association. 2013;54(1):33-9.

8. Tabish A, Sanat S, Syed AS, Raj S, Mahendra J. Assessment of effectiveness of different teaching methodologies in pharmacology for undergraduates at a rural medical college of Bastar region. Int J Biomed Res. 2015;6:512-7.

9. Prasad SR, Ravi H, Kudthni, Santosh R. A questionnaire based study of student's opinion in the teaching and learning methods in pharmacology in a medical school of India. International journal of basic and clinical pharmacology. 2016;5(6):2589-93.

Cite this article as: Patel AP, Katlam S. Dental students' perceptions and feedback on teaching and learning pharmacology. Int $\mathrm{J}$ Basic Clin Pharmacol 2017;6:2250-3. 